\title{
Association of Body Mass Index and Lipid Profiles in Children
}

\author{
Gülsen Meral1* ${ }^{*}$ Ayşegül Uslu1, Ali Ünsal Yozgatli², Faruk Akçay ${ }^{1}$ \\ ${ }^{1}$ Department of Children Health and Disease, Kagithane State Hospital, Istanbul, Turkey \\ ${ }^{2}$ Department of Obstetrics \& Gynecology, Kagithane State Hospital, Istanbul, Turkey \\ Email: "gulsenmeral@drgulsenmeral.com, ayseguluslu1@yahoo.com.tr, unsalyoz@hotmail.com, \\ farukakcay@mynet.com
}

Received 14 April 2015; accepted 31 May 2015; published 2 June 2015

Copyright (C) 2015 by authors and Scientific Research Publishing Inc.

This work is licensed under the Creative Commons Attribution International License (CC BY). http://creativecommons.org/licenses/by/4.0/

(c) (i) Open Access

\begin{abstract}
We examined the lipid values of obese and normal-weight children, to look if there is an association between Body Mass Index (BMI) and lipid profiles. Our study group included 100 volunteers (50 children with normal BMI and 50 with high BMI) who were admitted to Kagithane State Hospital Pediatrics Clinic for various reasons between July 2010 and May 2011. The inclusion criteria were as follows: age between 2 and 14 years, no chronic disease and no developmental defects. The high BMI group had significantly higher Low Density Lipoprotein (LDL) levels in comparison to the normal BMI group $(p<0.05)$. We also found that the high BMI group had higher cholesterol levels close to upper limit than the normal BMI group. We found high triglyceride levels not only in the high BMI group but also in the normal BMI group with a rate of $26 \%$ and $24 \%$ respectively. The difference of $2 \%$ was not significant. We advise that identification and treatment of elevated LDL cholesterol levels is of tremendous significance for obese children or adolescents for future cardiovascular disease risk in adulthood. In the light of these findings, we must not overlook cardiovascular risk in the normal BMI group children. We believe that necessary precautions must be taken for preventing overweight and dyslipidemia in early childhood. Accordingly, it is of paramount importance not only to reduce obesity in children and adolescents but also to monitor dyslipidemia in normal BMI children to avoid the subsequent risk for cardiovascular disease.
\end{abstract}

\section{Keywords}

Body Mass Index, Children, Cholesterol, Dyslipidemia

\section{Introduction}

Overall the global prevalence rate of obesity is 3.3\% reportedly. Some countries especially in Middle East, Latin

${ }^{*}$ Corresponding author. 
America and North America have higher rates. Overweight is showing an increasing global trend [1].

Current estimates suggest that up to 1.7 billion people are overweight or obese workdwide. Obesity is increasing all over the word. Over 115 million people are obese and have problems associated with obesity in developing countries [2]. Overweight problem is increasing continuously in children and adolescents at an alarming pace [2] [3].

Cardiovascular diseases are associated with risk factors such as obesity and dyslipidemia, which, if present during infancy, could continue throughout adult life [1] [4] [5].

High serum cholesterol HDL level is associated with longevity as evidence suggest. Low HDL cholesterol level is associated with an increased cardiovascular risk particularly if serum cholesterol and triglycerides are also elevated.

The most common primary lipid disorder familial combined hyperlipidemia which is an autosomal dominant condition occurring in $1 / 200$ people could not affect the results of our study with its low incidence.

The most common dyslipidemia of obesity is associated with increased triglyceride levels, decreased HDL levels and abnormal LDL cholesterol composition .Accepted risk factors for CVD are elevated LDL and decreased HDL [5] [6].

In this research, BMI and lipid profiles in children were examined to look for the association of obesity and dyslipidemia as was the case in adults.

\section{Material and Method}

Our study group enrolled 100 volunteers (50 children with normal BMI and 50 children with high BMI) who were admitted to Kagithane State Hospital Pediatrics Clinic consecutively for various reasons during July 2010May 2011 and met the criteria of our research and accepted to participate. The inclusion criteria were as follows: the age between 2 and 14 years, no chronic disease and no developmental defects.

The Ethics Committee of Şişli Etfal Education and Research Hospital approved the study protocol used for all participants.

Social and lifestyle issues were investigated with the help of a questionnaire.

$\mathrm{BMI}$ is calculated with weight/height ${ }^{2}$ formula. Obese, overweight and underweight are defined using BMI percentiles; children $>2$ years old with a BMI $>95$ th percentile meet the criterion for obesity, between 85th and 95th percentiles fall in the overweight range and a BMI < 5th percentile meet criterion for underweight (7).

Descriptive and observational study of 100 children and adolescents stratified BMI into two groups. They were classified as either normal weight or obese. Total cholesterol (T-chol), HDL and triglycerides (TG) were determined and LDL was calculated.

Acceptable total cholesterol level among children and adolescents is <170 mg/dL; borderline 170 - $199 \mathrm{mg} / \mathrm{dL}$; and high $>200 \mathrm{mg} / \mathrm{dL}$. Acceptable LDL cholesterol value is <110 mg/dL; borderline $110-129 \mathrm{mg} / \mathrm{dL}$; and high $>130 \mathrm{mg} / \mathrm{dL}$. HDL cholesterol value should be $>40 \mathrm{mg} / \mathrm{dL}$ ideally; the higher the better. We accept normal triglycerides levels for 2 and 5 year-olds to be 30 - $86 \mathrm{mg} / \mathrm{dL}$ (boys) and 32 - $99 \mathrm{mg} / \mathrm{dL}$ (girls), for the 6 - 11year-olds 31 - $108 \mathrm{mg} / \mathrm{dL}$ (boys) and 35 - $114 \mathrm{mg} / \mathrm{dL}$ (girls), for the 12 - 14 year-olds 36 - $138 \mathrm{mg} / \mathrm{dL}$ (boys) and $41-138 \mathrm{mg} / \mathrm{dL}$ (girls) [7].

After taking the blood into a vacuum tube including an activator \& gel, the sample was centrifuged at 4,000 rpm for 10 minutes and rested for 10 - 15 minutes. The serum was separated into the Beckmann couture LX20 analyzer. Cholesterol and lipid profile values were studied with auto analyzer by the photometric method.

For low levels of triglyceride below $400 \mathrm{mg} / \mathrm{dL}$, serum LDL cholesterol level was calculated by the following method.

LDL Cholesterol $=$ Total Cholesterol-Triglycerides/5-HDL Cholesterol.

For Triglyceride levels above $400 \mathrm{mg} / \mathrm{dL}$. LDL Cholesterol levels were assessed photometrically.

\section{Statistical Analysis}

For Statistical Analysis, NCSS (Number Cruncher Statistical System) 2007 \& PASS (Power Analysis and Sample Size) 2008 Statistical Software (Utah, USA) was used. Descriptive statistical methods (mean, standard deviation, median, frequency and ratio) were used along with Independent samples t test, for analyzing the differences of normally distributed variables between groups whereas Mann Whitney $\mathrm{U}$ test was used to analyze the differences of non-normally distributed variables. Pearson Chi-square test, Fisher's exact test and Yates' Chi-Square test were used to analyze the distribution of categorical variables among groups. The results were evaluated at $95 \%$ 
confidence interval and $p<0.05$ was accepted as statistically significant.

\section{Results}

Lipid profile of 50 children with normal BMI and 50 with high BMI were evaluated presenting to Kagithane State Hospital between 1 July 2010 and 1 May 2011.

The mean age of children with normal BMI were $7.8 \pm 2.65$ yrs, and those with high BMI were $10.73 \pm 2.78$ yrs. There were 23 (46.0\%) girls and 27 (54.0\%) boys in the normal BMI group and 21 (42.0\%) girls and 29 (58.0\%) boys in the high BMI group. No statistically significant difference with respect to gender was found between the two groups $(p>0.05)$ (Table 1$)$.

No statistically significant difference was observed between the groups regarding monthly income $(p>0.05)$ families' education levels and as to the rank among siblings (Table 2).

There was no statistically significant difference between normal BMI group and high BMI group as to HDL levels (Table 3).

A statistically significant difference was found as to LDL levels $(p<0.01)$. The high BMI group had significantly higher LDL levels compared to the normal BMI group $(p<0.05)$ (Table 4$)$.

We found that high BMI group had higher cholesterol levels close to upper limit in comparison to the normal BMI group (Table 5).

There was no significant difference in the triglyceride levels between the high and normal BMI groups ( $p>$

Table 1. Descriptive information.

\begin{tabular}{ccccc}
\hline & & Normal BMI (n = 50) & Obes BMI (n= 50) & p \\
\cline { 3 - 4 } Sex & Girl & N (\%) & N (\%) & \\
& Boy & $23(46.0 \%)$ & $21(42.0 \%)$ & $\mathbf{0 . 6 8 7}$ \\
\hline
\end{tabular}

Pearson Chi-Square test.

Table 2. Evaluation of characteristics of family.

\begin{tabular}{ccc}
\hline & Obese BMI (n = 50) & Normal BMI (n= 50) \\
\cline { 2 - 3 } & Mean \pm SD & Mean \pm SD \\
\hline Income (TL) & $1363.14 \pm 543.56$ & $1411.63 \pm 676.37$ \\
\hline
\end{tabular}

Independent samples t test.

Table 3. The assessment of HDL measurement.

\begin{tabular}{cccc}
\hline & & Normal BMI (N = 50) & Obese BMI (N = 50) \\
\cline { 3 - 4 } & & $\mathbf{N}(\%)$ & $\mathbf{p}(\%)$ \\
\hline
\end{tabular}

${ }^{+}$Fisher's exact test.

Table 4. The assessment of LDL measurement.

\begin{tabular}{|c|c|c|c|c|}
\hline & & Normal BMI $(n=50)$ & Obes BMI $(n=50)$ & \\
\hline & & N (\%) & N (\%) & $\boldsymbol{P}$ \\
\hline \multirow{3}{*}{ LDL } & ${ }^{++}$Normal & $43(86.0 \%)$ & $28(56.0 \%)$ & $0.002^{* *}$ \\
\hline & ${ }^{++}$Borderline & $6(12.0 \%)$ & 13 (26.0\%) & 0.126 \\
\hline & High & $1(2.0 \%)$ & $9(18.0 \%)$ & $0.016^{*}$ \\
\hline
\end{tabular}

Pearson Chi-Square test; ${ }^{++}$Yates Chi-Square test; ${ }^{*} p<0.05 ;{ }^{* *} p<0.01$. 
Table 5. Evaluation of cholesterol measurements.

\begin{tabular}{ccccc}
\hline & & Normal BMI (n = 50) & Obese BMI (n = 50) & p \\
\cline { 3 - 5 } & & $\mathbf{N}(\mathbf{\%})$ & $\mathbf{N}(\mathbf{\%})$ & $\mathbf{0 . 0 0 1}^{* *}$ \\
\hline \multirow{3}{*}{ Cholesterol } & ${ }^{+}$Normal & $45(90.0 \%)$ & $26(52.0 \%)$ & $\mathbf{0 . 0 0 1}^{* *}$ \\
& ${ }^{+}$Borderline & $4(8.0 \%)$ & $18(36.0 \%)$ & $\mathbf{0 . 1 1 2}$ \\
\hline
\end{tabular}

${ }^{+}$Fisher's exact test; ${ }^{* *} p<0.01$.

0.05). Contrary to expectations significant elevations were not found in triglyceride levels in children with increased BMI. Triglyceride values showed no significant difference with respect to gender in either groups ( $p>$ 0.05) (Table 6).

No significant difference was detected in behavior with respect to doing regular exercise between the two groups $(p>0.05)$. Both groups were not very much active in sports. There were significantly great differences with respect to sedentary activities like mean time of TV watch/ computer usage between the groups $(p<0.01)$. Obese children seemed to spend much longer time watching TV/using computer compared to normal-weight children $(p=0.013 ; p<0.05)$ (Table 7).

\section{Discussion}

Cardiovascular disease (CVD) seems to be the primary cause of mortality in developed countries and is laden with considerable morbidity. It ranks high on the list of causes of deaths in developing countries also. A variety of studies demonstrated that CVD risk factors such as obesity, high lipid profile, malnutrition and passive lifestyle begins in childhood and progress into adult life. Thus, it is of crucial importance to recognize and appreciate behavioral and physiological variables associated with CVD, early in life in order to save lives of children at risk [4] [8].

Recently, studies of overweight patients have observed a correlation between BMI and dyslipidemia. A study by Suarez et al. found that values of cholesterol close to potential risk level were found in 30\% of the population, $16 \%$ for triglycerides, $28 \%$ for LDL cholesterol. Lipid values were shown to be significantly different in overweight from those of general population [1]. Similar studies show that obesity is associated with abnormal values for cholesterol, triglycerides, LDL, HDL. Significant abnormalities were observed in lipid values of overweight children [8]-[10]. Overweight children have the higher LDL, triglyceride and cholesterol levels and the lower HDL in comparison to normal weight children [9]-[12].

Reck et al.'s study showed that abnormal lipid profiles were seen in $45.8 \%$ of overweight children [13]. A similar study showed that LDL cholesterol of obese children is 9 times high when compared to the normal weight children [14]. Yet there is a study showing no association between BMI and LDL levels [15].

Our result are in agreement with the findings of former studies demonstrating higher dyslipidemia values in obese children with LDL cholesterol concentrations significantly higher in the overweight children in comparison to normal weight children.

The study by Shamai et al. demonstrated that higher BMI was inversely associated with HDL [15]. Similar studies showed that HDL cholesterol is negatively associated with BMI level [16]-[18]. Sanlier observed that overweight students had significantly higher TG/HDL ratio and LDL/HDL ratio when compared to the normal and underweight students [19]. Similar to our study, there was no difference in HDL cholesterol between the normal and the high BMI group, either.

The study by Friedemann et al. pointed out that concentration of total cholesterol of obese children was 7.5 times as high as that of the normal weight children [14]. Other similar studies indicated that obese children have higher total cholesterol values in comparison to the normal children [16]-[18]. We also observed that the high BMI group had higher cholesterol levels close upper limit when compared to the normal BMI group. But there was no significant difference with respect to cholesterol levels between the two groups.

Recent studies have shown that high BMI is closely related with abnormal triglyceride levels [15]-[18]. Overweight students had significantly higher level triglyceride (TG) rates than normal and underweight students [19]. However, we found that there was no significant difference in the triglyceride levels between the high and 
Table 6. Evaluation of triglyceride measurements.

\begin{tabular}{ccccc}
\hline & & Normal BMI (n = 50) & Obese BMI (n = 50) & $\boldsymbol{p}$ \\
\cline { 3 - 4 } & & $\mathbf{N}(\mathbf{\%})$ & $\mathbf{N}(\mathbf{\%})$ & \\
\hline \multirow{2}{*}{ Nriglyceride } & Normal & $38(76.0 \%)$ & $37(74.0 \%)$ & $\mathbf{0 . 9 9 9}$ \\
& High & $12(24.0 \%)$ & $13(26.0 \%)$ & \\
\hline
\end{tabular}

${ }^{++}$Yates Chi-Square test.

Table 7. Evaluation of Time of doing exercise and TV watch/computer usage.

\begin{tabular}{|c|c|c|c|c|}
\hline & & Normal BMI $(n=50)$ & Obes BMI $(n=50)$ & \\
\hline & & n (\%) & n (\%) & $\boldsymbol{P}$ \\
\hline \multirow{4}{*}{ Doing exercise } & Yes & $4(8 \%)$ & $7(14 \%)$ & \multirow{3}{*}{0.613} \\
\hline & \multirow{3}{*}{ No } & & & \\
\hline & & 46 (92\%) & 43 (86\%) & \\
\hline & & Mean \pm SD (Median) & Mean \pm SD (Median) & ${ }^{+} \boldsymbol{p}$ \\
\hline \multicolumn{2}{|c|}{ TV watch /Computer usage time (hour) } & $3.90 \pm 2.07(3.00)$ & $5.02 \pm 2.46(3.00)$ & $0.004^{* *}$ \\
\hline
\end{tabular}

the normal BMI group.

Various studies have pointed out that obese patients with enlarged livers present with increased cholesterol synthesis, which may result from higher activity of the enzymes involved in cholesterol synthesis [20] [21].

In the light of our research, follow-up of lipid values provide an insight into future difficulties. Specialists should strongly urge their obese patients to have their lipid levels measured, enabling intervention at an early stage.

Given our results, we propose that obese children or adolescents with elevated LDL cholesterol levels be identified who will be at risk for cardiovascular diseases in adulthood. It is necessary to prevent obesity and dyslipidemias in an early age. Reducing obesity in children and adolescents precludes subsequent cardiovascular disease.

\section{Authors' Contribution and Background}

G.M, AU, FA, EE, AUY have made contributions in the conception and design of study and also in the acquisition, analysis and interpretation of data. They also have been involved in drafting and revision of the manuscript. All authors gave final approval of the version to be published.

All authors are actively practicing medicine in their branches for almost 7 years in this Institution (Kağıthane State Hospital) in a densely populated district of Istanbul.

\section{References}

[1] Suárez, N.P., Prin, M.C., Luciani, S.L., Pilottó, M.T., Dri, M.D. and Politti, I.R. (2008) Prevalencia de factores de riesgo de enfermedad cardiovascular: Obesidad y perfil lipídico. Anales de Pediatría, 68257-68263.

[2] de Onis, M. and Blössner, M. (2000) Prevelance and Trends of Overweight among Preschool Children in Developing Countries. American Journal of Clinical Nutrition, 72, 1032-1039.

[3] Li, Y., Dai, Q., Jackson, J.C. and Zhang, J. (2008) Overweight Is Associated with Decreased Cognitive Functioning among School-Age Children and Adolescents. Obesity, 16, 1809-1815. http://dx.doi.org/10.1038/oby.2008.296

[4] Nascimento, H., Costa, E., Rocha-Pereira, P., Rego, C., Mansilha, H.F., Quintanilha, A., et al. (2012) Cardiovascular Risk Factors in Portuguese Obese Children and Adolescents: Impact of Small Reductions in Body Mass Index Imposed by Lifestyle Modifications. The Open Biochemistry Journal, 6, 43-50. http://dx.doi.org/10.2174/1874091X01206010043

[5] Committee on Nutrition (1998) Cholesterol in Childhood. Pediatrics, 101, 141-147.

[6] Pinhas-Hamiel, O., Lerner-Geva, L., Copperman, N.M. and Jacobson, M.S. (2007) Lipid and Insulin Levels in Obese 
Children: Changes with Age and Puberty. Obesity, 15, 2825-2831. http://dx.doi.org/10.1038/oby.2007.335

[7] Kliegman, R.M., Stanton, B.F., Schor, N.F., Geme, J.W. and Behrman, R.E. (2011) Nelson Textbook of Pediatrics. 19th Edition, Elsevier Saunders, USA, 589.

[8] Manios, Y., Dimitriou, M., Moschonis, G., Kocaoglu, B., Sur, H., Keskin, Y., et al. (2004) Cardiovascular Disease Risk Factors among Children of Different Socioeconomic Status in Istanbul, Turkey: Directions for Public Health and Nutrition Policy. Lipids in Health and Disease, 3, 11-18. http://dx.doi.org/10.1186/1476-511X-3-11

[9] Romero-Velarde, E., Campollo-Rivas, O., Celis de la Rosa, A., Vásquez-Garibay, E.M., Castro-Hernández, J.F. and Cruz-Osorio, R.M. (2007) Factores de riesgo de dislipidemia en niños y adolescentes con obesidad. Salud Publica Mex, 49, 103-108. http://dx.doi.org/10.1590/S0036-36342007000200005

[10] Denke, M.A., Sempos, C.T. and Grundy, S.M. (1993) Excess Body Weight. An Underrecognized Contributor to High Blood Cholesterol Levels in White American Men. Archives of Internal Medicine, 153, 1093-1103. http://dx.doi.org/10.1001/archinte.1993.00410090045006

[11] Krauss, R.M., Winston, M., Fletcher, B.J. and Grundy, S.M. (1998) Obesity: Impact on Cardiovascular Disease. American Heart Association, 98, 1472-1476.

[12] Kouda, K., Fujita, Y., Nakamura, H., Takeuchi, H., Iki, M. (2011) Effect of Recovery from Obesity on Cardiovascular Risk Factors among Japanese Schoolchildren: The Iwata Population-Based Follow-Up Study. Journal of Epidemiology, 21, 370-375. http://dx.doi.org/10.2188/jea.JE20100140

[13] Korsten-Reck, U., Kromeyer-Hauschild, K., Korsten, K., Baumstark, M.W., Dickhuth, H.H. and Berg, A. (2008) Frequency of Secondary Dyslipidemia in Obese Children. Vascular Health and Risk Management, 4, 1089-1094.

[14] Friedemann, C., Heneghan, C., Mahtani, K., Thompson, M., Perera, R., Alison, M. and Ward, A.M. (2012) Cardiovascular Disease Risk in Healthy Children and Its Association with Body Mass Index: Systematic Review and MetaAnalysis. BMJ, 345, e4759. http://dx.doi.org/10.1136/bmj.e4759

[15] Shamai, L., Lurix, E., Shen, M., Novaro, G.M., Szomstein, S., Rosenthal, R., et al. (2011) Association of Body Mass Index and Lipid Profiles: Evaluation of a Broad Spectrum of Body Mass Index Patients Including the Morbidly Obese. Obesity Surgery, 21, 42-47. http://dx.doi.org/10.1007/s11695-010-0170-7

[16] Horta, B.L., Victora, C.G., Lima, R.C. and Post, P. (2009) Weight Gain in Childhood and Blood Lipids in Adolescence. Acta Paediatrica, 98, 1024-1028. http://dx.doi.org/10.1111/j.1651-2227.2009.01247.x

[17] Sánchez Bayle, M., Sánchez Bernardo, A., Peláez Gómez de Salazar, M.J., González Requejo, A., Martinoli Rubino, C. and Díaz Cirujano, A. (2006) Relationship between Lipid Profile and Body Mass Index. Five-Year Follow-Up in Children Aged 6-11 Years Old. The Rivas-Vaciamadrid Study. Anales de Pediatría, 65, 229-2933. http://dx.doi.org/10.1157/13092159

[18] Sarni, R.S., Suano de Souza, F.I., de Oliveira Schoeps, D., Catherino, P., Pires de Oliveira, M.C.C., Pessotti, C.F.X., et al. (2006) Relationship between Waist Circumference and Nutritional Status, Lipid Profile and Blood Pressure in Low Socioeconomic Level Pre-School Children. Arquivos Brasileiros de Cardiologia, 87, 153-158. http://dx.doi.org/10.1590/S0066-782X2006001500013

[19] Sanlier, N. and Yabanci, N. (2007) Relationship between Body Mass Index, Lipids and Homocysteine Levels in University Students. Journal of Pakistan Medical Association, 57, 491-495.

[20] Miettinen, T.A. and Gylling, H. (2000) Cholesterol Absorption Efficiency and Sterol Metabolism in Obesity. Atherosclerosis, 153, 241-248. http://dx.doi.org/10.1016/S0021-9150(00)00404-4

[21] Santosa, S., Varady, K.A., AbuMweis, S. and Jones, P.J. (2007) Physiological and Therapeutic Factors Affecting Cholesterol Metabolism: Does a Reciprocal Relationship between Cholesterol Absorption and Synthesis Really Exist? Life Sciences, 80, 505-514. http://dx.doi.org/10.1016/j.lfs.2006.10.006 